\title{
GERMINAÇÃO DE SEMENTES DE PORTA-ENXERTOS DE CITROS APÓS O ARMAZENAMENTO EM AMBIENTE REFRIGERADO ${ }^{1}$
}

\author{
DALMO LOPES DE SIQUEIRA²; JAYME FRANCISCO FERRARI DE VASCONCELLOS ${ }^{3}$; DENISE CUNHA \\ FERNANDES SANTOS DIAS ${ }^{3}$; WALTER ESFRAIM PEREIRA ${ }^{4}$.
}

\begin{abstract}
RESUMO - Este trabalho teve como objetivo avaliar o período de viabilidade das sementes dos porta-enxertos limoeiros- 'Cravo' e 'Volkameriano', tangerineira- 'Cleópatra' e citrumeleiro- 'Swingle' armazenadas em embalagem permeável sob temperatura controlada de $5-7^{\circ} \mathrm{C}$ por 150 dias. A cada 30 dias, foram avaliadas a germinação em laboratório e a emergência das plântulas em casa de vegetação. Determinou-se o grau de umidade das sementes em cada época de testes. O armazenamento nas condições citadas induziu menor velocidade de germinação nas sementes de 'Cravo' e 'Volkameriano', as quais não tiveram a germinação prejudicada quando apresentavam umidade próxima a 5\%. Houve correlação altamente significativa entre teor de água e germinação nas sementes de 'Cleópatra' e 'Swingle'. Para a manutenção da viabilidade das sementes destes porta-enxertos, deve-se procurar manter o seu grau de umidade em torno de 20\%. As sementes dos limoeiros- 'Cravo' e 'Volkameriano' apresentaram maior velocidade de germinação e emergência que os demais porta-enxertos, enquanto as da tangerineira- 'Cleópatra' apresentaram menor velocidade de emergência. Sementes de citrumeleiro'Swingle' e tangerineira- ‘Cleópatra' não germinaram após armazenamento por 60 e 90 dias, respectivamente.
\end{abstract}

Termos para indexação: sementes, citros, viabilidade, armazenamento.

\section{SEED GERMINATION OF CITRUS ROOTSTOCKS AFTER COOLING CONDITIONS STORAGE}

\begin{abstract}
The present work was carried out in order to verify the viability period of the rootstocks 'Rangpur' lime, 'Volkameriano' lemon, 'Cleópatra' mandarin and 'Swingle' citrumelo seeds stored in permeable package at $5-7^{\circ} \mathrm{C}$ for 150 days. The Germination in laboratory, seedling emergence in greenhouse and seed moisture content were performed each 30 days. Seed storage in that conditions reduced the speed of emergence index in the 'Rangpur' and 'Volkameriano' seeds. The germination of these rootstocks seeds weren't reduced when the seed moisture content was near 5\%. There was highly significative correlation between seed water content and germination porcentage of 'Cleópatra' and Swingle' seeds. For viability maintenance to seeds of these rootstocks, moisture content could be kept around 20\%. The 'Rangpur' and 'Volkameriano' seeds showed higher vigor as compared with the other rootstocks, while 'Cleópatra' seeds presented lower speed of emergence index.
\end{abstract}

Index terms: seeds, citrus, viability, storage.

\section{INTRODUÇÃO}

A muda cítrica é formada, quase em sua totalidade, usando a técnica de enxertia denominada borbulhia, sendo que a propagação seminífera não é mais utilizada há várias décadas, exceto para a obtenção dos porta-enxertos.

A diversificação dos porta-enxertos vem ocorrendo na citricultura nacional. Em 1970, o limoeiro- ‘Cravo’ (Citrus limonia Osbeck) correspondia a 99\% dos porta-enxertos plantados no Estado de São Paulo. Sua participação foi reduzida para $72 \%$ no final da década de 80. A tangerineira- 'Cleópatra' ( Citrus reshni Hort. ex Tan.), por sua vez, teve sua participação aumentada de 0,3\% em 1970 para 24\% entre os anos de 1984 e 1988 (Silva et al., 1990). Dados do Fundecitrus (1996) revelam que limoeiro- 'Cravo', tangerineira- 'Cleópatra' e citrumeleiro-'Swingle' [Citrus paradisi Macf. x Poncirus trifoliata (L.) Raf.] respondem, respectivamente, por $85 \%, 9 \%$ e $3 \%$ dos porta-enxertos utilizados no mesmo Estado. A tendência à diversificação no uso de porta-enxertos vem aumentando com resultados promissores. Segundo Pompeu
Júnior et al. (1986), o emprego de um único porta-enxerto para todas as variedades de copa não permite, provavelmente, atender às características inerentes de cada cultivar, impedindo que a planta manifeste todo o seu potencial produtivo, além de constituir-se em inconveniente problema no caso de moléstias endêmicas.

O transporte a longas distâncias e a comercialização de sementes de qualidade, bem como época de maturação dos portaenxertos, época de semeadura e clima são fatores que fazem com que o armazenamento de sementes para formação de portaenxertos de citros seja um processo importante para os viveiristas.

Experiências demonstraram que altas temperaturas reduzem rapidamente o poder germinativo e que as sementes de limoeiro- 'Cravo' são melhor conservadas se tratadas com fungicida e embaladas em saco plástico a $8^{\circ} \mathrm{C}$ (Montenegro \& Salibe, 1960). Usberti (1979) e Usberti \& Felipe (1980) verificaram que as melhores temperaturas para germinação de sementes do limoeiro- 'Cravo 'encontram-se entre $25^{\circ} \mathrm{Ce} 35^{\circ} \mathrm{C}$. Por outro lado, King et al. (1981) observaram que sementes com $5 \%$ de umidade

1 (Trabalho 099/2001). Recebido: 08/05/2001. Aceito para publicação: 02/05/02.

2 Prof. Adjunto, D.S., - Universidade Federal de Viçosa, Depto. de Fitotecnia, 36571-000, Viçosa, MG.

3 Acadêmico de Agronomia - Universidade Federal de Viçosa, Depto. de Fitotecnia, 36571-000, Viçosa, MG.

4 Pós-graduando em Fitotecnia - Universidade Federal de Viçosa, Depto. de Fitotecnia, 36571-000, Viçosa, MG. 
e armazenadas a temperaturas abaixo de $5^{\circ} \mathrm{C}$ mantêm melhor o poder germinativo quando comparadas àquelas armazenadas com teores de água e temperatura mais elevados. Para Koller et al. (1993), a conservação de sementes de Poncirus trifoliata foi melhor em geladeira a $5^{\circ} \mathrm{C}$ do que em câmara a $12^{\circ} \mathrm{C}$ e $47 \%$ de umidade relativa.

Algumas variedades utilizadas para porta-enxertos, como tangerineira- 'Cleópatra', Poncirus trifoliata e seus híbridos vêm apresentando acentuados problemas de germinação que, na maioria das vezes, estão relacionados ao armazenamento inadequado das sementes.

Neste contexto, o presente trabalho teve como objetivo avaliar a viabilidade de sementes de porta-enxertos cítricos armazenadas em embalagens permeáveis, sob temperatura controlada.

\section{MATERIAL E MÉTODOS}

O trabalho foi desenvolvido no Departamento de Fitotecnia da Universidade Federal de Viçosa, em Minas Gerais, em condições de casa de vegetação e de laboratório.

As sementes dos limoeiros- 'Cravo', 'Volkameriano', tangerineira- 'Cleópatra' e citrumeleiro- 'Swingle' foram extraídas de frutos maduros, coletados no pomar do Setor de Fruticultura da UFV, em 15-07-97. Após a extração, as sementes foram lavadas em água corrente para a retirada da mucilagem. A secagem foi feita à sombra, durante três dias. As sementes deformadas ou deterioradas ou imaturas foram descartadas, e as restantes foram contadas e pesadas em balança com precisão de $0,001 \mathrm{~g}$, calculando-se o número médio de sementes por fruto e por quilo, para cada variedade.

Posteriormente, as sementes foram tratadas com o fungicida Captan 500 PM (100 g i.a./100 kg de sementes) e semeadas em casa de vegetação e laboratório. O restante das sementes foi armazenado em sacos de papel e mantidas em ambiente refrigerado $\left(5-7^{\circ} \mathrm{C}\right)$. Foram realizadas semeaduras, em casa de vegetação e em laboratório, em intervalos de 30 dias, durante 150 dias, totalizando seis avaliações, entre 18-07-97 e 1812-97.

Antes de cada semeadura, foi feita a determinação do teor de umidade das sementes pelo método da estufa a $105 \pm 3^{\circ} \mathrm{C}$ por 24 horas, utilizando-se duas subamostras de 40 sementes por variedade. $\mathrm{O}$ grau de umidade foi calculado com base no peso úmido (Brasil, 1992).

Para a semeadura em casa de vegetação, o substrato utilizado foi a vermiculita (Vermifloc tipo 34) acondicionada em bandejas para germinação. Foram semeadas duas subamostras de 50 sementes por variedade, e a porcentagem de emergência foi avaliada de cinco em cinco dias, do $50^{\circ}$ ao $90^{\circ}$ dia .

Em laboratório, o substrato utilizado foi o papel toalha umedecido com água destilada equivalente a 2,5 vezes o peso do substrato seco. Foram semeadas quatro subamostras de 50 sementes que foram mantidas em germinador a $30^{\circ} \mathrm{C}$, e a porcentagem de plântulas normais obtidas foi avaliada a cada três dias, do $21^{\circ}$ ao $45^{\circ}$ dia.

Foram calculados, ainda, os Índices de Velocidade de Germinação(IVG), em laboratório, e de Velocidade de Emergência (IVE), em casa de vegetação, para cada porta-enxerto e tratamento, segundo Nakagawa (1994). Para o cálculo do IVG, foram computadas as plântulas normais com altura e comprimento radicular mínimo de $3 \mathrm{~cm}$. Em casa de vegetação, foi estipulada uma altura mínima de $2,5 \mathrm{~cm}$ para a contagem das plântulas normais emergidas.

Os Índices de Velocidade de Germinação e de Emergência foram calculados somente para os porta-enxertos que atingiram porcentagem de emergência ou germinação mínima de $10 \%$ ao final do período de observação.

O delineamento experimental utilizado foi o inteiramente casualizado, com quatro repetições.

Foi feita, ainda, análise de regressão para o efeito das épocas de armazenamento, sendo as equações selecionadas com base na significância dos seus efeitos, utilizando-se do teste F. Foram calculados, também, os coeficientes de correlação simples entre a porcentagem de germinação e o teor de umidade das sementes para os quatro porta-enxertos.

\section{RESULTADOS E DISCUSSÃO}

Na Tabela 1, encontram-se os resultados do número médio de sementes por fruto e do número médio de sementes por quilo para cada porta-enxerto. Observa-se que as sementes do citrumeleiro- 'Swingle' apresentaram maior número médio de sementes por fruto e peso em relação às demais.

Pela Figura 1, observa-se que o grau de umidade das sementes dos porta-enxertos citrumeleiro- 'Swingle' e tangerineira- 'Cleópatra', após a secagem $(21,42 \%$ e 18,41\%, respectivamente), foi maior que o apresentado pelas sementes dos limoeiros- 'Cravo' e 'Volkameriano' (respectivamente, 10,38\% e $11,23 \%$ ). O grau de umidade foi acentuadamente reduzido após trinta dias de armazenagem das sementes para todos os portaenxertos testados. Após este período, manteve-se na faixa de $4 \%$ a $6 \%$ nos quatro porta-enxertos, até 150 dias de armazenamento. A redução mais lenta do teor de água das sementes aos trinta dias de armazenamento, apresentada pelo citrumeleiro- 'Swingle', pode ser atribuída ao maior tamanho e peso dessas sementes (Tabela 1). King \& Roberts (1980) afirmaram que a perda de umidade é mais lenta em sementes de maior tamanho do que em sementes menores.

Apesar de a redução da umidade parecer responsável pela não-germinação das sementes em algumas espécies de citros, as sementes do limoeiro- 'Cravo' mantiveram o poder germinativo na faixa de $60 \%$ em laboratório, alcançando valores em casa de vegetação de $93 \%$ aos 60 dias de armazenamento e $80 \%$ aos 150 dias, mesmo com teores de água inferiores a 5\% (Figura 2).

O limoeiro-'Volkameriano' apresentou comportamento semelhante ao ‘Cravo' até os 60 dias de armazenamento. Após este período, as sementes do 'Volkameriano' tiveram seu poder germinativo reduzido de $87 \%$, aos 60 dias de armazenamento, a valores em torno de $60 \%$, a partir de 90 dias de armazenagem, nos testes realizados em casa de vegetação, e inferiores a $30 \%$ após 120 de armazenamento nos testes em laboratório (Figura 2)

Ainda na Figura 2, observa-se que tanto as sementes da tangerineira- 'Cleópatra' quanto as do citrumeleiro- 'Swingle' tiveram sua germinação significativamente reduzida aos trinta dias de armazenamento. As sementes da tangerineira- 'Cleópatra',

Rev. Bras. Frutic., Jaboticabal - SP, v. 24, n. 2, p. 317-322, agosto 2002 
TABELA 1 - Número médio de sementes por fruto e por quilo de quatro variedades de porta- enxertos de citros.

\begin{tabular}{lcc}
\hline Variedade & $\mathrm{N}^{\circ}$ de sementes/fruto & $\mathrm{N}^{\circ}$ de sementes/kg \\
\hline Tangerineira-Cleópatra & 11 & 9.900 \\
Citrumeleiro-Swingle & 17 & 5.100 \\
Limoeiro-Volkameriano & 15 & 8.800 \\
Limoeiro-Cravo & 09 & 13.000 \\
\hline
\end{tabular}
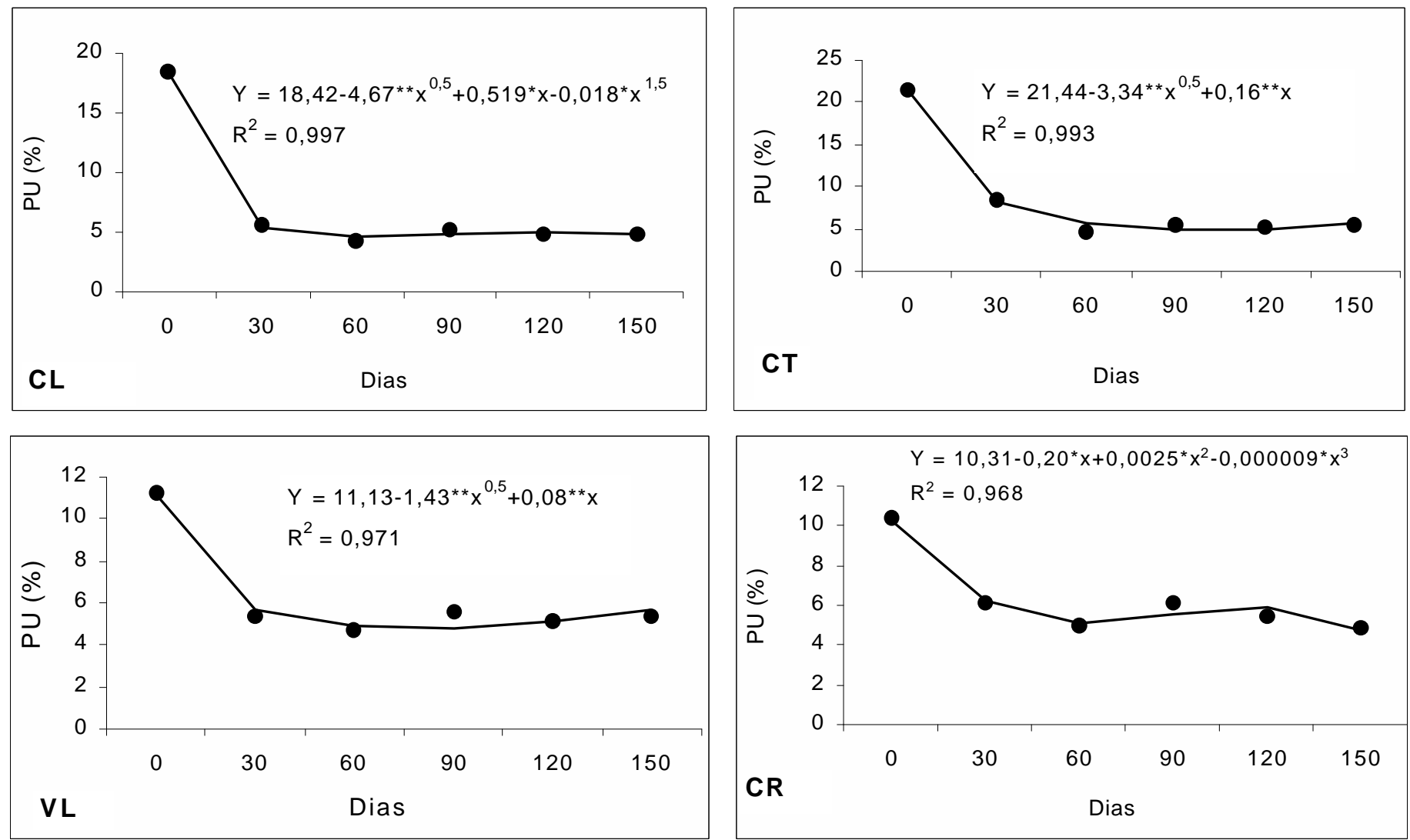

*, **; Significativo a $5 \%$ e $1 \%$ de probabilidade, respectivamente, pelo teste $\mathrm{F}$.

FIGURA 1 - Percentagem de umidade (PU) de sementes da tangerineira- 'Cleópatra' (CL) do citrumeleiro- 'Swingle' (CT), e dos limoeiros-'Volkameriano' (VL) e ‘Cravo' (CR), em função do tempo de armazenamento (expresso em dias).

porém, com grau de umidade inferior a 5\%, alcançaram valores de germinação de $23 \%$ em casa de vegetação, aos 60 dias de armazenamento. As sementes do citrumeleiro- 'Swingle' apresentaram germinação reduzida a valores entre $0 \%$ e $3 \%$ a partir de 60 dias de armazenamento, tanto em casa de vegetação quanto em laboratório.

Houve correlação altamente significativa entre a porcentagem de germinação e o grau de umidade das sementes de tangerineira- 'Cleópatra' e citrumeleiro- 'Swingle' , tanto nos testes realizados em germinador quanto em casa de vegetação (Figura 3). A correlação entre grau de umidade e porcentagem de germinação não foi significativa para as sementes dos limoeiros- 'Volkameriano' e 'Cravo' em condições de casa de vegetação, indicando menor velocidade de emergência provocada pelo armazenamento das sementes destes porta-enxertos, visto que o período de observação dos testes em casa de vegetação foi de
90 dias, enquanto em laboratório foi de 45 dias (Figura 3).

Os resultados obtidos mostraram que as sementes das espécies de citros estudadas apresentaram comportamento diferenciado em função do armazenamento devido ao decréscimo no seu grau de umidade, confirmando as observações de Montenegro \& Salibe, (1960). Roberts (1973) classificou as espécies de Citrus spp. como apresentando comportamento intermediário entre o ortodoxo e o recalcitrante durante o armazenamento. Hong \& Ellis (1995), referindo-se às sementes de café e citros, observaram haver variação entre espécies de um mesmo gênero quanto ao comportamento no armazenamento.

O grau de umidade crítico para a conservação das sementes de limoeiro- 'Cravo' diferiu do obtido por Montenegro \& Salibe (1960), que determinaram um valor em torno de $8 \%$. No presente trabalho, teores de água ligeiramente inferiores a $5 \%$ não limitaram a germinação das sementes deste porta-enxerto. 

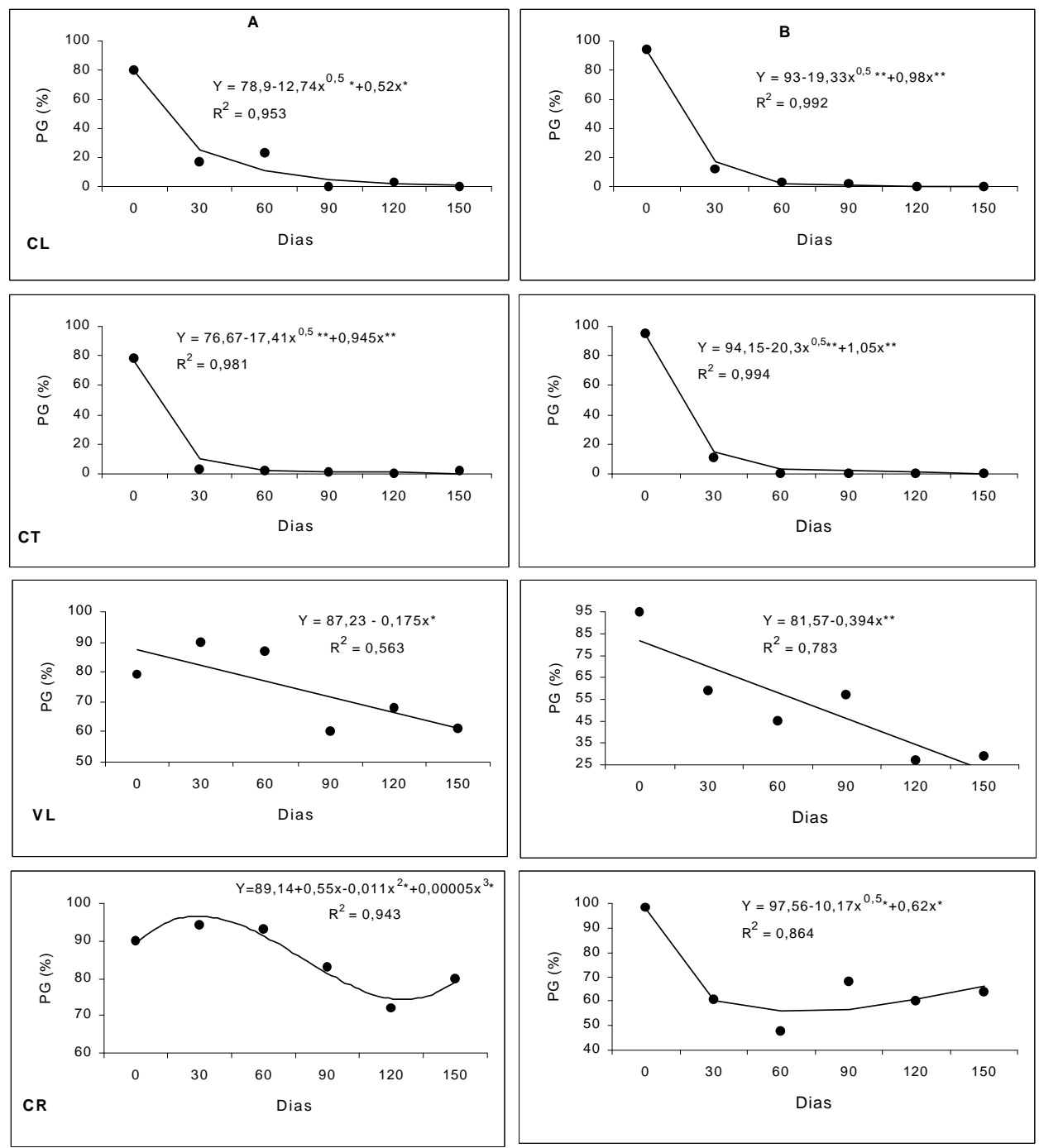

*,**; Significativo a $5 \%$ e $1 \%$ de probabilidade, respectivamente, pelo teste $\mathbf{F}$.

FIGURA 2 - Percentagem de germinação (PG) de sementes da tangerineira - 'Cleópatra' (CL), do citrumeleiro- ‘Swingle ‘ (CT), e dos limoeiros- 'Volkameriano' (VL) e ‘Cravo' (CR), na casa de vegetação (A) e no laboratório (B), em função do tempo de armazenamento.
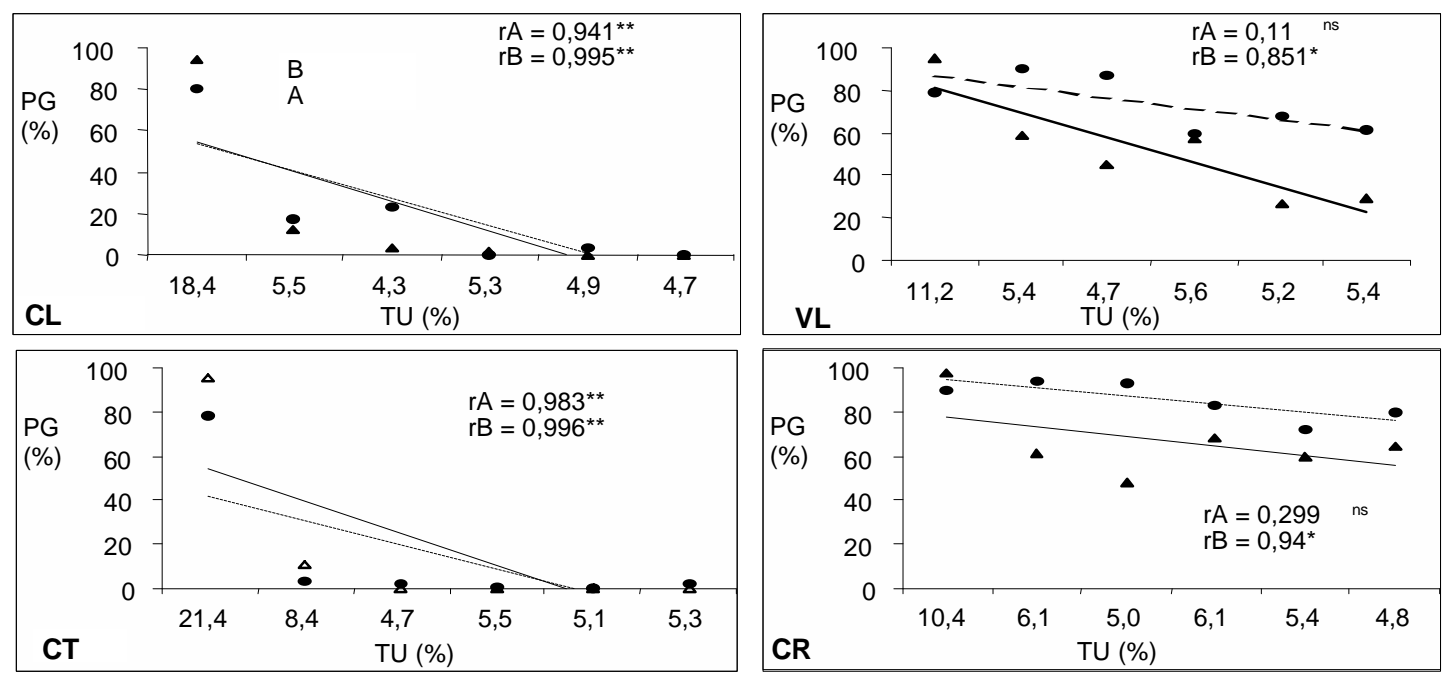

ns, *,**; Não significativo, significativo a $5 \%$ e $1 \%$ de probabilidade, respectivamente, pelo teste $\mathbf{t}$.

FIGURA 3 - Correlação entre percentagem de germinação (PG) e teor de umidade (\%) das sementes da tangerineira - 'Cleópatra' (CL), dos limoeiros-'Volkameriano' (VL) e 'Cravo' (CR) e do citrumeleiro-'Swingle' (CT), na casa de vegetação (A) e no laboratório (B). 

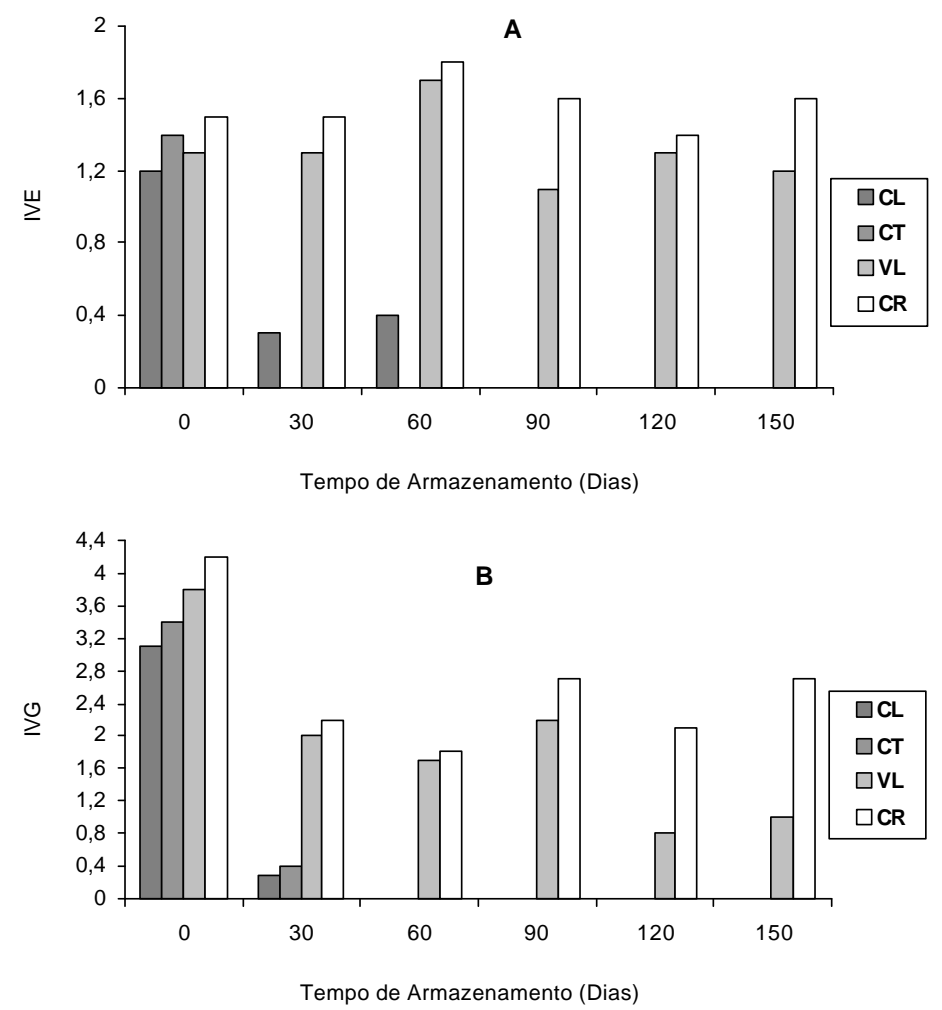

FIGURA 4 - Índice de velocidade de emergência (IVE) e índice de velocidade de germinação (IVG) de sementes da tangerineira'Cleópatra' (CL), do citrumeleiro- 'Swingle' (CT), e dos limoeiros-'Volkameriano' (VL)e 'Cravo' (CR), na casa de vegetação (A) e no laboratório (B), em função do tempo de armazenamento.

Os resultados obtidos para o citrumeleiro-'Swingle' equiparam-se a outros, obtidos para híbridos de Poncirus trifoliata, como citrange-'Troyer' ( $P$. trifoliata X C. sinensis) (Montenegro \& Salibe, 1960; Button et al., 1971).

Os índices de velocidade de germinação e de velocidade de emergência obtidos comprovaram que as sementes da tangerineira- 'Cleópatra' apresentaram menor velocidade de germinação e emergência (Figura 4), mesmo com grau de umidade superior ao mostrado pelas sementes do limoeiro- 'Cravo' e 'Volkameriano' não armazenadas (época 0). Observa-se, ainda, que as sementes de 'Cleópatra' apresentaram valores médios de $80 \%$ de emergência em casa de vegetação e $94 \%$ de germinação em laboratório, aos 90 dias e 45 dias de armazenamento, respectivamente.

Tanto as sementes do citrumeleiro- 'Swingle' quanto as da tangerineira- 'Cleópatra', apesar de apresentarem graus de umidade mais elevados na ocasião da semeadura imediata, mostraram velocidade de germinação menor, em laboratório, em relação aos outros porta-enxertos. Em laboratório, as sementes deste porta-enxerto apresentaram velocidade de germinação menor que as do limoeiro- 'Cravo' e 'Volkameriano', sendo que as sementes do limoeiro- 'Cravo' apresentaram maior velocidade de germinação tanto em condições de casa de vegetação quanto em germinador (Figura 4).

O aumento na velocidade de emergência para as sementes que foram armazenadas em relação àquelas semeadas imediatamente, pode ser explicado pelo incremento da temperatura ambiente durante o período de condução dos testes, visto que a casa de vegetação não possuía controle de condições ambientais.

\section{CONCLUSÕES}

1. As sementes do limoeiro-'Cravo' com grau de umidade ligeiramente inferior a $5 \%$ apresentam boa conservação do poder germinativo (80\%), por 150 dias, em sacos de papel.

2. Para a manutenção da viabilidade de sementes do citrumeleiro 'Swingle', o grau de umidade das sementes deve estar ao redor de $20 \%$.

3. As sementes dos quatro porta-enxertos testados apresentaram índices de velocidade de emergência (IVE) semelhantes em casa de vegetação quando semeadas logo após a colheita.

4. Quando submetidas ao armazenamento, as sementes dos limoeiros- 'Cravo' e 'Volkameriano' apresentaram IVE significativamente superior às demais, demonstrando maior vigor.

5. O armazenamento induziu velocidade de germinação para os porta-enxertos 'Volkameriano'e 'Cravo'.

\section{REFERÊNCIAS BIBLIOGRÁFICAS}

BRASIL. Ministério da Agricultura. Regras para análise de sementes. Brasília: SNAD/DNDV/CLAV,1992.365p.

BUTTON, J.; BORNMAN, C. H.; HACKLAND, B. A. Effect of some presowing treatments on the germination of Poncirus trifoliata and Troyer citrange seeds. Citrus and Subtropical Fruit Journal, Parklands, v. 45, n.1, p.9-11, 1971.

FUNDECITRUS. Amarelinho, o papel do citricultor. Revista 
Fundecitrus. Araraquara, v. 7, n. 78, set/out. 1996.

HONG, T.D.; ELLIS, R.H. Interespecific variation in seed storage behaviour within two genera - Coffea and Citrus. Seed Science \& Technology,Zurich, v. 23, n.1, p.165-181, 1995.

KING, M.W.; SOESTINA, U.; ROBERTS, E.H. The dry storage of Citrus seeds. Annals of Botany, London, v.48, p.865-872, 1981.

KING, M.W.; ROBERTS, E.H. Maintenance of recalcitrant seeds in storage. In: CHIN, H.F. \& ROBERTS, E.H. (Ed.), Recalcitrant crop seeds. Kuala Lumpur: Tropical Press, 1980. p.53-89.

KOLLER, O. C. Citricultura: laranja, limão e tangerina. Porto Alegre: Ed. Rígel, 1994. 445p.

KOLLER, O. L.; STUKER, H.; VERONA, L. F. Efeito da umidade, temperatura de estocagem e duração da estocagem sobre a germinação de Poncirus trifoliata e de outros porta-enxertos de cítrus. Revista Brasileira de Fruticultura, Cruz das Almas, v.15, n.1, p.27-33, 1993.

MONTENEGRO, H. W. S.; SALIBE, A. A. Conservação de sementes de porta-enxertos para citros. Revista da Agricultura, Piracicaba, v. 35, n. 2, p.109-114, 1960.

NAKAGAWA, J. Testes de vigor baseados na avaliação das plântulas. In: VIEIRA, R. D.; CARVALHO, N. M.. Testes de vigor em sementes. Jaboticabal: FUNEP, 1994. p. 49-85.

POMPEU JÚNIOR, J.; FIGUEIREDO, J. O. de.; TEÓFILO SOBRINHO, J.; JORGE, J. P. N.; JACON, J. R. Competição de clones de limão- 'Cravo' e limão-'Volkameriano' como porta-enxerto para laranja-'Natal'. In: CONGRESSO BRASILEIRO DE FRUTICULTURA, 8., 1986, Brasília. Anais... Brasília; EMBRAPA-DDT/ CNPq, 1986. p.147-151.

ROBERTS, E.H. Predicting the storage life of seeds. Seed Science \& Technology, Zurich, v.1, n.2, p.499-514, 1973

SILVA, M. M.; POMPEU JÚNIOR, J.; BERETTA, M. J. G.; ROSSETI, V.; NEGRI, J. D. Diversificação de porta-enxertos em decorrência do declínio dos Citros no estado de São Paulo. Revista Laranja, Cordeirópolis, v. 11, n. 1, p.309-321, 1990.

USBERTI, R. Estudo da germinação de sementes de limão-Cravo (Citrus reticulata var. austera Hib. Swingle): condições de umidade e armazenamento e relações hormonais. Campinas: Universidade Estadual de Campinas, 1979. 70p.

USBERTI, R.; FELIPE, G. M. Viabilidade de sementes de Citrus limonia Osb. com baixo teor de umidade, armazenadas em diferentes temperaturas. Pesquisa Agropecuária Brasileira, Brasília, v. 15, n. 4, p.393-397, 1980. 